\title{
BMJ Open Adolescents' beliefs, attitudes and social norms with regard to smoking and sports: a qualitative study
}

\author{
Ingri Grimnes Olsen (D) , ${ }^{1}$ Heike H Garritsen, ${ }^{1}$ len van de Goor, ${ }^{2}$ Anton E Kunst, ${ }^{1}$ \\ Andrea D Rozema ${ }^{2}$
}

To cite: Olsen IG, Garritsen HH, van de Goor I, et al. Adolescents' beliefs, attitudes and social norms with regard to smoking and sports: a qualitative study. BMJ Open 2021;11:e046613. doi:10.1136/ bmjopen-2020-046613

- Prepublication history and additional supplemental material for this paper are available online. To view these files, please visit the journal online (http://dx.doi.org/10.1136/ bmjopen-2020-046613).

Received 08 December 2020 Accepted 27 July 2021
Check for updates

(C) Author(s) (or their employer(s)) 2021. Re-use permitted under CC BY-NC. No commercial re-use. See rights and permissions. Published by BMJ.

${ }^{1}$ Department of Public and Occupational Health, Amsterdam UMC Location AMC, Amsterdam, The Netherlands

${ }^{2}$ Tranzo Scientific Centre for Care and Welfare, Tilburg University, Tilburg, The Netherlands

Correspondence to Ingri Grimnes Olsen; ingri.olsen@outlook.com

\section{ABSTRACT}

Objectives The aim of this study is to explore the beliefs, attitudes and social norms of Dutch adolescents with regard to smoking and sports. In addition, we examine whether there are differences between adolescents at sports clubs with versus without an outdoor smoke-free policy (SFP).

Design Qualitative design in the form of focus group interviews.

Setting Focus group interviews $(n=27)$ were conducted at 16 sports clubs in the Netherlands. Soccer, tennis, field hockey and korfball clubs were included. Focus group discussions were transcribed verbatim and analysed thematically using MAXQDA.

Participants 180 adolescents aged $13-18$ years old were included in the study. All participants signed an informed consent form. For participants younger than 16 years, parental consent was required.

Results With respect to smoking in relation to sports, participants had mostly negative beliefs (ie, smoking has a negative effect on health and sports performance), attitudes (ie, sports and smoking are activities that do not fit together; at sports clubs smoking is not appropriate), and social norms (ie, it is not normal to smoke at sports clubs). The same beliefs, attitudes and social norms were expressed by participants at both sports clubs with and without an outdoor SFP. However, argumentation against smoking was more detailed and more consistent among participants at sports clubs with an outdoor SFP.

Conclusion Adolescents have negative beliefs, attitudes and social norms with regard to smoking in relationship to sports. Outdoor SFP at sports clubs might reinforce these negative associations. These findings point to the potential importance of sports in the prevention of adolescent smoking.

\section{INTRODUCTION}

Smoking initiation often takes place during adolescence $^{1}$ and is influenced by many factors, including beliefs (the feeling of being certain that something exists or is true), attitudes (positive or negative predispositions towards a behaviour), and social norms (the social pressure to perform a behaviour). ${ }^{2}$ These three constructs shape an individual's intentions which, according to the Theory of Planned Behavior (TPB), influence changes

\section{Strengths and limitations of this study}

First study to use qualitative methods to explore in greater depth the views of adolescents regarding smoking and sports.

- Data were collected through focus group discussions with both genders at 16 sports clubs located in all four regions of the Netherlands.

- Need for peer approval may have induced socially desirable responses.

in smoking behaviour. ${ }^{3}$ The TPB has proven to predict adolescents' smoking behaviour, ${ }^{24}$ for example, negative attitudes towards smoking predict intentions not to smoke. ${ }^{25}$ In addition to such individual-level factors, the smoking behaviour of adolescents is influenced by the different activities they undertake, the environments in which they live and by their peers. Performing sports and being present at sports clubs may play an important role in relation to smoking behaviour, since many adolescents participate in sports, ${ }^{26}$ peers are present and sports clubs are environments where important role models are present.

Previous studies have examined the relation between smoking and sports among adolescents. ${ }^{27-11}$ According to these studies, adolescents performing sports are less likely to smoke than those not performing sports. The likelihood of smoking depends on the level of involvement in sports ${ }^{467}$ and the kind of sport, ${ }^{8}$ with higher involvement and highendurance sports being more protective. More generally, adolescents who engage in sports with a greater level of physical activity are less likely to smoke or smoke fewer cigarettes per day than adolescents who engage less. ${ }^{12-18}$

The inverse association between smoking and sports may have several explanations. Sports participation is not only associated with actual smoking, but also with attitudes towards smoking. Positive attitudes towards 
exercise are found to be associated with negative attitudes towards smoking. ${ }^{2}$ Next to this, adolescents participating in sports may have an increased awareness of the detrimental effects on health and performance. They receive more information about health and health risks and may therefore be more aware of the negative consequences of smoking. ${ }^{9}$

Yet, the evidence explaining the links between smoking and sports remains meagre. Previous studies on smoking and sports used quantitative approaches, either as part of randomised trials ${ }^{2} 711$ or longitudinal studies. ${ }^{8-10}$ To the best of our knowledge, there are no published studies that used a qualitative approach with the aim to gain in-depth knowledge of adolescents' beliefs, attitudes and social norms towards smoking and sports, while this is needed to fully understand adolescents' perceptions.

Internationally, an increasing number of sports clubs are implementing outdoor smoke-free policies (SFPs), among others, to prevent secondhand smoking and to protect youth against smoking. ${ }^{19}$ Outdoor SFPs can help discourage the onset of adolescent smoking by reducing the visibility of smoking, limiting the opportunities to smoke and communicating that smoking is socially unacceptable. ${ }^{20-23}$ However, to the best of our knowledge, there are no published studies on adolescent smoking in relationship to outdoor SFP at their sports clubs.

The aim of this study is to explore the beliefs, attitudes and social norms of Dutch adolescents with regard to smoking and sports. In addition, we examine whether there are differences between adolescents at sports clubs with versus without an outdoor SFP. We aim to gain an in-depth understanding of adolescents' perspectives by conducting focus group discussions.

\section{METHODS \\ Design}

A qualitative approach was chosen to obtain in-depth information about adolescents' beliefs, attitudes and social norms with regard to smoking and sports. A qualitative design is a particularly useful method when investigating an under-researched area, or when participants' views on the topic are unknown. ${ }^{24}$

\section{Participants}

A total of 16 Dutch sports clubs were included in the study, of which there were 8 with an outdoor SFP and 8 without an outdoor SFP (see table 1). The sports clubs were located in different regions in the Netherlands. Four major Dutch sports were included: soccer, tennis, field hockey and korfball. These sports differ in terms of socioeconomic status (SES) of their members and in team composition. Participating clubs $(\mathrm{n}=16)$ did not significantly differ from non-participating clubs $(n=49)$ in terms of type of sports and level of urbanisation. Sports clubs were contacted either face-to-face or by phone, email and/or letter. The main reasons for non-participation

\begin{tabular}{|c|c|c|c|}
\hline & $\begin{array}{l}\text { No of sports } \\
\text { clubs } \\
n=16\end{array}$ & $\begin{array}{l}\text { With an } \\
\text { outdoor SFP } \\
n=8\end{array}$ & $\begin{array}{l}\text { Without an } \\
\text { outdoor } \\
\text { SFP } \\
n=8\end{array}$ \\
\hline \multicolumn{4}{|l|}{ Sports } \\
\hline Soccer & 5 & 2 & 3 \\
\hline Korfball & 4 & 2 & 2 \\
\hline Field hockey & 4 & 2 & 2 \\
\hline Tennis & 3 & 2 & 1 \\
\hline \multicolumn{4}{|l|}{ Size (members) } \\
\hline$<250$ & 4 & 1 & 3 \\
\hline $250-500$ & 3 & 3 & 0 \\
\hline $500-1000$ & 6 & 3 & 3 \\
\hline $1000-1500$ & 3 & 1 & 2 \\
\hline \multicolumn{4}{|l|}{ Level of urbanity } \\
\hline Highly urbanised & 3 & 2 & 1 \\
\hline Urbanised & 4 & 3 & 1 \\
\hline $\begin{array}{l}\text { Moderately } \\
\text { urbanised }\end{array}$ & 2 & 1 & 1 \\
\hline Rural & 6 & 2 & 4 \\
\hline Highly rural & 1 & 0 & 1 \\
\hline
\end{tabular}

SFP, smoke-free policy.

were lack of interest $(\mathrm{n}=22)$, not having enough participants $(n=11)$ and lack of time $(n=8)$.

At each sports club, focus group discussions $(n=27)$ were conducted with adolescents aged 13-18 years old. Per club, two focus group discussions were conducted, with an exception of five clubs where only one focus group discussion was conducted because there were not enough boys or girls to form groups for both genders. Groups were divided by gender as adolescents' responses might be influenced by the presence of the other gender. ${ }^{25} \mathrm{~A}$ total of 180 adolescents participated in the study. Table 2 presents the characteristics of the participants, including gender, age and smoking status.

\section{Patient and public involvement}

No patients were involved.

\section{Procedure}

The field study was conducted from May 2019 to December 2019 in collaboration with Sportief Advies (SA), a Dutch organisation that supports projects with regard to sports and culture. SA was responsible for recruiting the sports clubs.

\section{Focus group discussions}

Focus group discussions were conducted by the first two authors (IGO and HHG) and took place at the participating sports clubs. The discussions were audio-recorded and lasted on average 20 min (range 12-29). All participants signed an informed consent form. For participants 
Table 2 Characteristics of the participants $(n=180)$

\begin{tabular}{|c|c|c|c|c|c|c|}
\hline & $\begin{array}{l}\text { No of } \\
\text { participants } \\
n=180\end{array}$ & $\%$ & $\begin{array}{l}\text { With a } \\
\text { SFP } \\
n=89\end{array}$ & $\%$ & $\begin{array}{l}\text { Witho } \\
\text { SFP } \\
n=91\end{array}$ & $\%$ \\
\hline \multicolumn{7}{|l|}{ Gender } \\
\hline Boy & 72 & 40.0 & 37 & 41.6 & 35 & 38.5 \\
\hline Girl & 108 & 60.0 & 52 & 58.4 & 56 & 61.5 \\
\hline 14 & 35 & 19.4 & 18 & 20.2 & 17 & 18.7 \\
\hline 15 & 61 & 33.9 & 33 & 37.1 & 28 & 30.8 \\
\hline 16 & 44 & 24.4 & 20 & 22.5 & 24 & 26.4 \\
\hline 17 & 23 & 12.8 & 11 & 12.4 & 12 & 13.2 \\
\hline Non-smoker & 168 & 93.3 & 87 & 97.8 & 81 & 89.0 \\
\hline
\end{tabular}

*Defined by whether or not they smoked in the last 30 days.

SFP, smoke-free policy.

younger than 16 years, parental consent was required. Participants received a $€ 10$ gift voucher for their participation.

At the start of each discussion, the interviewer explained the purpose of the study and the participants' rights as confidential participants in scientific research. Hereafter, the interviewer asked the participants to fill out a questionnaire regarding their gender, age and smoking status. All focus groups started with initial 'icebreaking' questions (How long have you been a member of this club? How would you describe the club?), followed by questions based on the psychological constructs (beliefs, attitudes and social norms) of the TPB. The topic guide can be found in online supplemental appendix 1. The interviewer aimed to keep the group discussion focused on the topic and to ensure that all participants had the opportunity to contribute (using phrases such as 'And what do you think about this?').

\section{Analysis}

Focus group discussions were transcribed verbatim and analysed using MAXQDA. Thematic analysis was applied, which is a qualitative method for identifying, analysing and reporting patterns or themes within a dataset. ${ }^{24}$ The coding was performed inductively by the first author (IGO). To ensure intercoder reliability, the second author (HHG) co-coded 10 transcripts. Inconsistencies in coding were discussed until consensus was reached. Thereafter, the list of codes was further analysed by combining similar codes and forming larger codes. Next, the larger codes were divided into beliefs, attitudes, and social norms on the individual and sports club level, based on the definitions of the three concepts.

\section{RESULTS}

Four categories were derived from the data: (1) beliefs on individual level, (2) attitudes on individual level, (3) attitudes on sports club level and (4) social norms on sports club level (see table 3). We first describe the findings within these four categories, followed by the differences that were found at sports clubs with an outdoor SFP versus without an outdoor SFP.

\section{Individual level}

Beliefs

According to the majority of the participants, smoking negatively affects sports performance (see table 3-beliefs on individual level). Participants mentioned that those negative effects are mainly physical, that is, a decline in physical condition, decreased lung capacity and breathlessness. Participants consistently stated that the decline in physical condition diminishes sports performance. Although participants mostly mentioned the physical effects of smoking, a few participants mentioned that smoking could have a negative effect on mental health and responsiveness.

However, a few participants emphasised that smoking does not affect technical aspects of sports performance such as the throwing technique in korfball. Highly skilled athletes may perform well even if they smoke. Similarly, some current or past smokers emphasised that they did not experience an effect of starting/quitting smoking on their sports performance. Participants also expected only minor negative effects for those who do not smoke frequently; adolescents participating in sports experience negative effects only when smoking daily or weekly. 


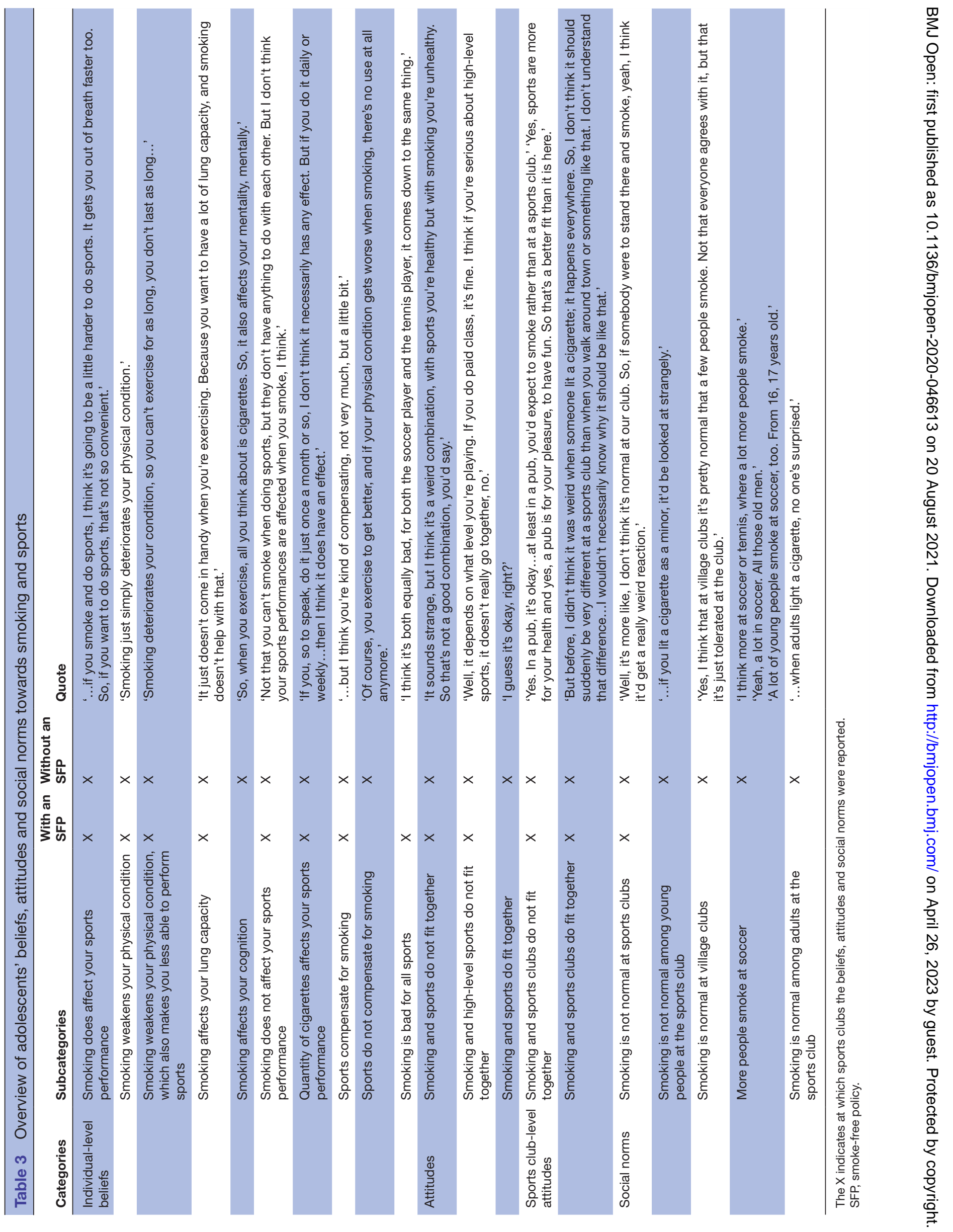


Furthermore, a few participants argued that participating in sports can compensate for the negative effects of smoking on one's physical condition in general, that is, one's condition may be less affected by smoking if one participates in sports. However, none of the participants said that sports would prevent the harmful effects of smoking with regard to disease, such as the onset of lung cancer.

\section{Attitudes}

The majority of the participants believed that smoking and sports do not fit together (see table 3-attitudes on individual level). This attitude was commonly based on the straightforward observation that sports are healthy, while smoking is unhealthy. Participants thought that smoking is especially not appropriate for adolescents participating in sports on a higher level, while it may be acceptable for adolescents participating in sports on a lower level, and especially for those who play sports mainly for fun.

\section{Sports club level}

\section{Attitudes}

According to the participants, sports clubs are not somewhere smoking ought to be present (see table 3-attitudes on club level). Their straightforward reasoning is that sports clubs are oriented towards sports and health, which are at odds with the habit of smoking. Participants recognised that sports clubs are places where people like to come together and that smoking could accompany social activities. Nevertheless, as the social function of clubs is subordinate to their athletic, competitive function, sports clubs are not the place where smoking should be tolerated to the same degree as elsewhere (such as at outdoor bars/restaurants or at nearby schools).

\section{Social norms}

Most participants were clear regarding the descriptive social norm: it is not normal to smoke at sports clubs (see table 3-social norms on club level). This applies especially to adolescent smoking. Youth smoking is not considered as normal behaviour at sports clubs, while smoking among adults may be more common at some sports clubs.

Some participants reported that there are differences between sports clubs regarding the social norms of smoking. It was argued that smoking was more normal at clubs in small villages, where teams are often composed of friend groups and the main goal is to have fun when practising sports. Furthermore, smoking was said to be more normal at soccer clubs than in other types of sports such as at 'high class' hockey clubs.

\section{Differences between sports clubs with versus without an outdoor SFP}

Overall, participants at sports clubs with versus without an outdoor SFP reported the same types of beliefs, attitudes and social norms with regard to smoking and sports. However, there were some differences in the frequency and detail in which arguments were mentioned. Participants at sports clubs with an outdoor SFP were more specific and consistent in their reporting of negative beliefs and attitudes towards smoking in relation to sports ('Smoking just simply deteriorates your physical condition'). At clubs without an outdoor SFP, participants expressed more uncertainty in their statements ('I guess it's ok, right?'). In addition, the latter participants more often mentioned exceptions or situations where smoking could be tolerated.

\section{DISCUSSION \\ Key findings}

This study shows that adolescents have mostly negative beliefs (ie, smoking has a negative effect on health and sports performance), attitudes (ie, sports and smoking are activities that do not fit together; at sports clubs smoking is not appropriate), and social norms (ie, it is not normal to smoke at sports clubs) with regard to smoking and sports. Even though adolescents at sports clubs with an outdoor SFP expressed the same beliefs, attitudes and social norms as those at clubs without an outdoor SFP, they had more detailed and consistent arguments against smoking.

\section{Interpretations of these findings}

The finding that most adolescents believe that smoking has a negative effect on sports performance is in line with existing research that suggests that athletes believe smoking will hurt their performance and compromise their chances of success. They are more likely to perceive smoking as a danger to their health. ${ }^{9}$ Compared with those not participating in sports, adolescents participating in sports are more exposed to health information and health counselling about the harmful effects of smoking (eg, from their coach or trainer).

A consistently voiced attitude of most participants was that smoking and sports do not fit together. Bebetsos et $\mathrm{al}^{2}$ also found that positive attitudes and behaviours towards exercise are associated with negative attitudes and behaviours towards smoking. Encouraging adolescents to practise sports can reinforce the positive attitudes towards smoking, given that smoking is perceived to conflict with sports. ${ }^{16}{ }^{6}$ However, it is important to be aware that participating in sports might have the adverse effect of enhancing the use of alcohol. Systematic reviews have concluded that participating in sports is associated with a lower use of tobacco and illicit drugs, although that it tends to be associated with an increased use of alcohol. ${ }^{15} 16$ 26-28 Smoke-free sports policies preferably include measures to prevent alcohol use by adolescents.

According to adolescents, sports clubs are places where young people do not smoke and are not allowed to smoke. While these social norms may logically derive from the beliefs and attitudes discussed above, they may be reinforced by the fact that parents are often present at sports clubs. When adolescents especially do not want parents and peers to know about their cigarette use, the 
presence of parents and peers can deter adolescents from smoking at sports clubs. ${ }^{6}$

Even though adolescents do not associate sports clubs with youth smoking, smoking by adults is perceived as more normal. This might relate to the view that sports clubs should protect children and adolescents against smoking, but have no 'patronising' role towards adult members. ${ }^{629}$ Our participants argued that youth in particular should be protected against smoking to prevent the onset of smoking.

Smoking is thought to be normal at clubs in small villages and at soccer clubs. This variability in descriptive social norms indicates that adolescents differentiate between types of sports and sports clubs. Adolescents perceive clubs in smaller villages as being more convivial, with more emphasis on social functioning than sports performance. Similarly, the perception that smoking is more normal at soccer clubs may be derived from the lower SES of most soccer clubs and the perception that smoking is mostly a habit of people with a low SES. ${ }^{30}$

We found that argumentation was more detailed and consistent among adolescents at sports clubs with an outdoor SFP. This may reflect the fact that implementation of an SFP is found to be followed by changes in the beliefs, attitudes and social norms of those exposed to the SFP, possibly because of reductions in the visibility of smoking and its perceived acceptability. ${ }^{20} 223132$ Thus, implementation of an outdoor SFP at sports clubs may have strengthened adolescents' negative beliefs, attitudes and social norms towards smoking and sports.

\section{Strengths and limitations}

This is the first study to use qualitative methods to explore in greater depth the views of adolescents regarding smoking and sports. We performed focus group discussions at different sports clubs located in all four regions of the Netherlands. Focus group discussions have the advantage of producing rich data from the interaction between group members. As a result of this interaction, focus group discussions generate more information than the sum of individual inputs. Adolescents participating in focus group discussions hear the opinions of others, which can encourage them to respond to these ideas or suggest new ideas of their own. ${ }^{25} 33$ Nevertheless, one limitation needs to be considered. The intense need for peer approval and declining social trust during adolescence can affect the information adolescents are willing to share in a focus group, ${ }^{34}$ and may have induced socially desirable responses. ${ }^{35}$ However, although most adolescents expressed negative beliefs, attitudes and social norms with regard to smoking and sports, other adolescents also felt free to express opposing views. Moreover, a few additional interviews that we had with individual adolescents, including smokers, disclosed no other views than those voiced in the focus groups.

\section{CONCLUSION}

Adolescents' negative beliefs, attitudes and social norms with regard to smoking and sports are well worth the attention of those interested in preventing adolescent smoking. With many adolescents involved in sports, sports participation could potentially be a major contributor to preventing tobacco use. First, programmes aimed at changing adolescents' smoking behaviour could refer to values associated with sports, or link up with sports activities. Second, sports can be a protective factor in settings where smoking may still be prevalent, including areas near schools, by stimulating that these settings are dedicated to sports activities. Third, health-promotion activities at sports clubs may focus on the fact that some adolescents still have positive beliefs, attitudes and social norms with regard to smoking and sports. Finally, the potentially protective role of SFPs, including smoke-free sports clubs, must be acknowledged in order to promote their adoption at increasingly more sports clubs.

Contributors IGO, HHG, IvdG, AEK and ADR have made substantial contributions to conception and design, acquisition, data and interpretation of data. IGO and HHG analysed the data. IGO drafted the article. HHG, ADR, AEK and IvdG revised it critically for important intellectual content. All authors read and approved the final manuscript.

Funding This work was supported by ZonMw (project number 531003016, 2018). Competing interests None declared.

Patient consent for publication Not required.

Ethics approval The Medical Ethics Review Committee of the Academic Medical Center confirmed that the Dutch Medical Research Involving Human Subjects Act (WMO) did not apply to this study and that an official approval was not required (W20_318 \# 20.369).

Provenance and peer review Not commissioned; externally peer reviewed. Data availability statement No additional data available.

Supplemental material This content has been supplied by the author(s). It has not been vetted by BMJ Publishing Group Limited (BMJ) and may not have been peer-reviewed. Any opinions or recommendations discussed are solely those of the author(s) and are not endorsed by BMJ. BMJ disclaims all liability and responsibility arising from any reliance placed on the content. Where the content includes any translated material, BMJ does not warrant the accuracy and reliability of the translations (including but not limited to local regulations, clinical guidelines, terminology, drug names and drug dosages), and is not responsible for any error and/or omissions arising from translation and adaptation or otherwise.

Open access This is an open access article distributed in accordance with the Creative Commons Attribution Non Commercial (CC BY-NC 4.0) license, which permits others to distribute, remix, adapt, build upon this work non-commercially, and license their derivative works on different terms, provided the original work is properly cited, appropriate credit is given, any changes made indicated, and the use is non-commercial. See: http://creativecommons.org/licenses/by-nc/4.0/.

ORCID iD

Ingri Grimnes Olsen http://orcid.org/0000-0002-2035-1348

\section{REFERENCES}

1 World Health Organization. Tobacco use in adolescence. Available: https://www.euro.who.int/_data/assets/pdf_file/0016/303532/ HBSC-No.7_factsheet_Tobacco.pdf

2 Bebetsos E, Papaioannou A, Theodorakis Y. University Students' Attitudes and Behaviours Towards Smoking and Exercise. European Journal of Physical Education 2003;8:29-51.

3 Ajzen I. The theory of planned behavior. Organ Behav Hum Decis Process 1991;50:179-211. 
4 O'Callaghan FV, Callan VJ, Baglioni A. Cigarette use by adolescents: attitude-behavior relationships. Subst Use Misuse 1999;34:455-68.

5 Higgins A, Conner $M$. Understanding adolescent smoking: the role of the theory of planned behaviour and implementation intentions. Psychol Health Med 2003;8:173-86.

6 Sigfúsdóttir ID, Thorlindsson T, Kristjánsson AL, et al. Substance use prevention for adolescents: the Icelandic model. Health Promot Int 2009;24:16-25.

7 Horn K, Branstetter S, Zhang J, et al. Understanding physical activity outcomes as a function of teen smoking cessation. J Adolesc Health 2013;53:125-31.

8 Mays D, Luta G, Walker LR, et al. Exposure to Peers who smoke moderates the association between sports participation and cigarette smoking behavior among non-white adolescents. Addict Behav 2012;37:1114-21.

9 Melnick MJ, Miller KE, Sabo DF, et al. Tobacco use among high school athletes and nonatieletes: results of the 1997 youth risk behavior survey. Adolescence 2001;36:727-47.

10 Rodriguez D, Audrain-McGovern J. Team sport participation and smoking: analysis with general growth mixture modeling. $J$ Pediatr Psychol 2004;29:299-308.

11 Serraino D, Fachin C, Feltrin O, et al. Sport activity and cigarette smoking among young and adult athletes from the northeastern part of Italy. Eur J Epidemiol 1988;4:497-502.

12 Aaron DJ, Dearwater SR, Anderson R, et al. Physical activity and the initiation of high-risk health behaviors in adolescents. Med Sci Sports Exerc 1995;27:1639-45.

13 Abrams K, Skolnik N, Diamond JJ. Patterns and correlates of tobacco use among suburban Philadelphia 6th- through 12th-grade students. Fam Med 1999;31:128-32.

14 Coulson NS, Eiser C, Eiser JR. Diet, smoking and exercise: interrelationships between adolescent health behaviours. Child Care Health Dev 1997;23:207-16.

15 Diehl K, Thiel A, Zipfel S, et al. How healthy is the behavior of young athletes? A systematic literature review and meta-analyses. J Sports Sci Med 2012;11:201-20.

16 Lisha NE, Sussman S. Relationship of high school and college sports participation with alcohol, tobacco, and illicit drug use: a review. Addict Behav 2010;35:399-407.

17 Pate RR, Heath GW, Dowda M, et al. Associations between physical activity and other health behaviors in a representative sample of US adolescents. Am J Public Health 1996;86:1577-81.

18 Thorlindsson T, Vilhjalmsson R. Factors related to cigarette smoking and alcohol use among adolescents. Adolescence 1991;26:399.
19 Frazer K, Callinan JE, McHugh J, et al. Legislative smoking bans for reducing harms from secondhand smoke exposure, smoking prevalence and tobacco consumption. Cochrane Database Syst Rev 2016;2:CD005992.

20 Alesci NL, Forster JL, Blaine T. Smoking visibility, perceived acceptability, and frequency in various locations among youth and adults. Prev Med 2003;36:272-81.

21 Eisenberg ME, Forster JL. Adolescent smoking behavior: measures of social norms. Am J Prev Med 2003;25:122-8.

22 Kelly BC, Vuolo M, Frizzell LC, et al. Denormalization, smoke-free air policy, and tobacco use among young adults. Soc Sci Med 2018;211:70-7.

23 Wakefield M, Forster J. Growing evidence for new benefit of clean indoor air laws: reduced adolescent smoking. Tob Control 2005;14:292-3.

24 Braun V, Clarke V. Using thematic analysis in psychology. Qual Res Psychol 2006;3:77-101.

25 Krueger RA, Casey MA. Focus groups: a practical guide for applied research. California: Sage Publications, 2009.

26 Martens MP, Dams-O'Connor K, Beck NC. A systematic review of college student-athlete drinking: prevalence rates, sport-related factors, and interventions. J Subst Abuse Treat 2006;31:305-16.

27 Mays D, Gatti ME, Thompson NJ. Sports participation and alcohol use among adolescents: the impact of measurement and other research design elements. Curr Drug Abuse Rev 2011;4:98-109.

28 Kwan M, Bobko S, Faulkner G, et al. Sport participation and alcohol and illicit drug use in adolescents and young adults: a systematic review of longitudinal studies. Addict Behav 2014;39:497-506.

29 Park S-H. Smoking and adolescent health. Korean J Pediatr 2011;54:401-4.

30 Hiscock R, Bauld L, Amos A, et al. Socioeconomic status and smoking: a review. Ann N Y Acad Sci 2012;1248:107-23.

31 Giles-Corti B, Clarkson JP, Donovan RJ, et al. Creating smokefree environments in recreational settings. Health Educ Behav 2001;28:341-51.

32 Weber MD, Bagwell DAS, Fielding JE, et al. Long term compliance with California's smoke-free workplace law among bars and restaurants in Los Angeles County. Tob Control 2003;12:269-73.

33 Heary C, Hennessy E. Focus groups versus individual interviews with children: a comparison of data. Ir J Psychol 2006;27:58-68.

34 Norris AE, Aroian KJ, Warren S, et al. Interactive performance and focus groups with adolescents: the power of play. Res Nurs Health 2012;35:671-9.

35 Horner SD. Using focus group methods with middle school children. Res Nurs Health 2000;23:510-7. 